Dept. Int. Med., Fac. Vet. Med., Beni-Suef.

\title{
EVALUATION OF TRIALS OF VACCINATION AND REVACCINATION OF CATTLE USING RB51 AND S19 VACCINES BY MONITORING OF THE SEROLOGICAL RESPONSE AND SHEDDING OF THE VACCINAL STRAINS
}

(With 4 Tables)

\author{
By \\ R.A. AZZAM \\ (Received at 12/6/2007)
}

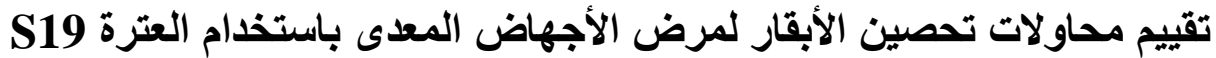

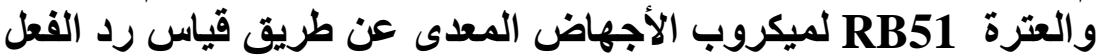
المناعى واقراز العترة اللقاحية من الأبقار المحصنية

$$
\text { رجب عزام على }
$$

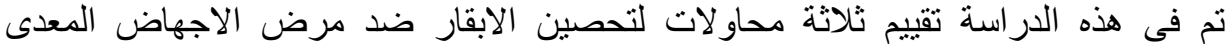

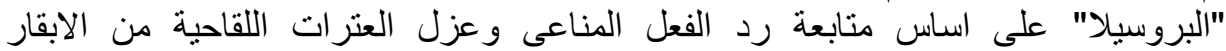

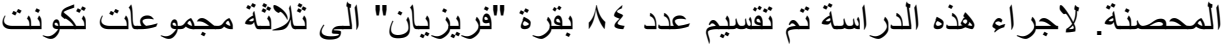

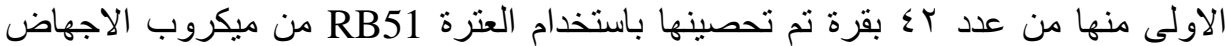

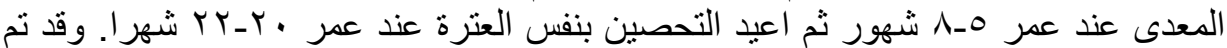

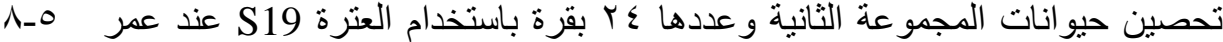

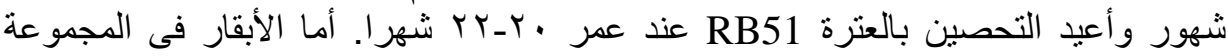

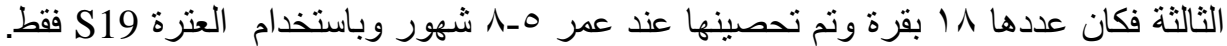

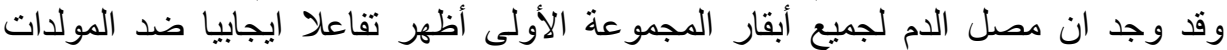

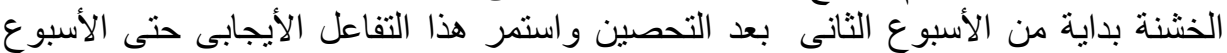

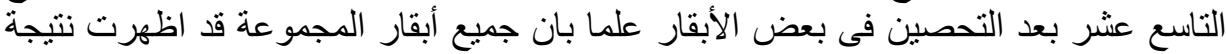

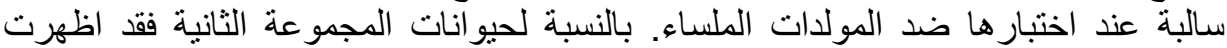

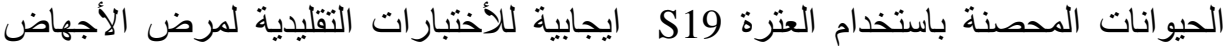

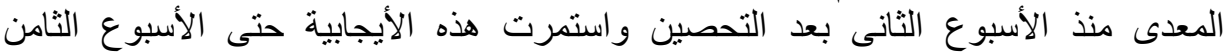

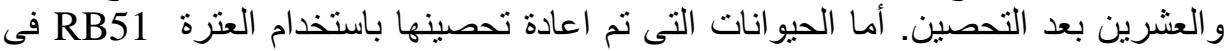

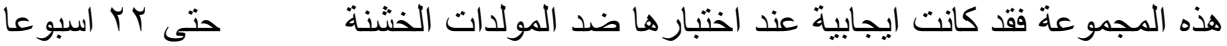

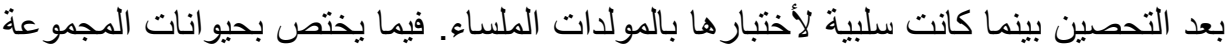

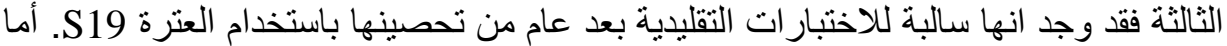

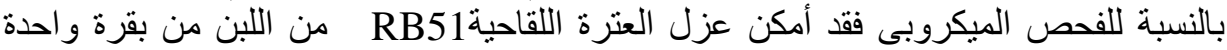

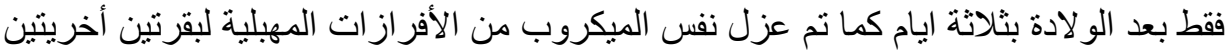

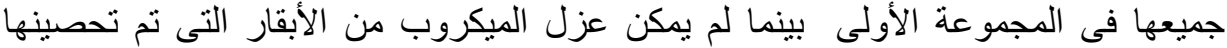




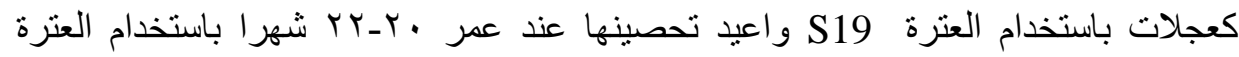
.RB51

\section{SUMMARY}

In this study, evaluation of three trials of vaccination of cattle against brucellosis through monitoring of the serological immune response and shedding of the vaccinal strains was carried out. For this purpose, a total of 84 Friesian cows were divided into three groups. The first group consisted of 42 cows that were vaccinated at the age of 5-8 months with Brucella abortus SRB51 vaccine and then revaccinated at the age of 20-22 months with the same vaccine. Animals of the second group (24 cows) were vaccinated at the age of 5-8 months with Brucella abortus S19 then revaccinated with RB51 vaccine at the age of 20-22 months, while animals of the third group (18) were vaccinated only at the age of 5-8 months with Brucella abortus S19. Sera of all vaccinates of the first group reacted positively at the second week post vaccination and some animals continued up to 19 weeks post vaccination using rough antigen. Employing smooth antigen, the conventional tests showed negative results. Sera of S19 vaccinated animals seroconverted at the $2^{\text {nd }}$ week post vaccination and some continued up to 28 weeks post vaccination using the conventional tests. RB51 revaccinated animals in this group developed antibodies against the rough antigen up to 22 weeks post vaccination and no antibodies against the smooth antigen were detected. Examination of animals that were vaccinated only using S19 at 5-8 months after one year revealed that all animals were serologically negative. Bacteriologically, one cow from the first group shed the RB51vaccinal strain in milk three days post parturition and two cows shed the organism in their vaginal discharges. Cows that were vaccinated as calves with $\mathrm{S} 19$ and revaccinated as adults with RB51 showed no organisms in their milk or vaginal discharges.

Key words: Brucellosis, vaccination, serological response

\section{INTRODUCTION}

Brucellosis is a worldwide serious disease. It still affects large numbers of animals in Egypt causing abortion and infertility. The disease is transmissible to occupationally exposed humans. Brucella organisms are Gram-negative facultative intracellular bacteria that infect macrophages where they persist and evade immune elimination, Covert 
et al. (2005). Chronic infections are thought to be due to their ability to avoid the killing mechanisms within the host cells.

Prevention of bovine brucellosis is achieved by using live attenuated vaccines, Adone and Ciuchini (2001). Recently a new official calfhood vaccine; Brucella abortus S RB51 has been approved in the United States for use in brucellosis eradication programs. Brucella abortus SRB51 is a lipopolysaccharide $\mathrm{O}$ antigen-deficient mutant of the virulent strain 2308 of Brucella abortus, Schurig et al. (2002). It has been documented to be protective in cattle and not to induce antibodies that interfere with brucellosis serological surveillance tests which identify antibodies to liopopolysaccharides, Stevens et al. (1995) and Olsen et al. (1997).

In Egypt, Brucella melitensis biovar3 remains the prevalent type of brucella affecting cattle, Salem and Hosein (1990), Hosein et al. (2002) and Soliman, H.S. (2006). Several efforts have been made to control the disease through the use of vaccines including Brucella abortus SRB51. The present study was carried out to evaluate some trials of vaccination and revaccination of cattle using RB51 and S19 vaccines. The serological immune response in cows vaccinated with Brucella abortus S RB51 (as calfhood vaccination and revaccinated with the same vaccine as adults) and cows vaccinated with Brucella abortus S19 (as calfhood vaccination and revaccinated with Brucella abortus SRB51 as adults) in the light of possibility of shedding the vaccinal strains were investigated.

\section{MATERIALS and METHODS}

1 - Animals: A total of 84 Friesian cows in Damitta Governorate were used in this study through the period (January 2004 - April 2006)

2 - Experimental design: Three groups of animals were randomly selected

Group I: A total of 42 cows were vaccinated at the age of 5-8 months with Brucella abortus SRB51 vaccine $\left(3 \times 10^{9}\right.$ S.C) and revaccinated with the same vaccine at 20-22 months of age (Most of these cows were pregnant at this time).

Group II: A total of 24 cows were vaccinated at the age of 5-8 months with Brucella abortus S19 (5 $\times 10^{10} \quad$ S.C) and revaccinated with Brucella abortus SRB51 (3 x10 9 S.C) vaccine at 20-22 months of age. (Also most of the cows were pregnant).

Group III: A total of 18 cows were vaccinated as calves of 5-8 months age with Brucella abortus S19 only. 


\section{3 - Samples:}

a. Blood serum samples were collected from all cows after vaccination and revaccination weekly up to 30 weeks.

b. Colostrum and milk samples and vaginal discharges all from cows were collected at the $1^{\text {st }}, 3^{\text {rd }}$ and $7^{\text {th }}$ days after parturition.

\section{4 - Vaccines:}

a. Brucella abortus SRB51 vaccine U.S.Vet. Licence No. 188 Professional Biological Company 4950 York street Denever USA.

b. Brucella abortus S19 vaccine; it was obtained from the Veterinary Serum and Vaccine Research Institute, Abbasia, Cairo, Egypt.

\section{5 - Serological tests:}

a. Tube Agglutination Test (TAT), was carried out using smooth and rough antigens. The test was carried out according to Alton et al. (1988).

b. Rose Bengal Test (RBT), was carried out according to Morgan et al. (1978).

c. Buffered Acidified Plate antigen Test (BAPAT), was carried out according to Alton et al. (1988).

\section{6 - Bacteriological examination:}

Isolation, identification and typing of brucella organisms were carried out according to Alton et al. (1988)

\section{RESULTS}

Table 1: Monitoring the serological immune response of cows of group I

\begin{tabular}{|c|c|c|c|c|}
\hline \multicolumn{2}{|c|}{ Used vaccine } & \multirow{2}{*}{$\begin{array}{c}\text { Age of } \\
\text { vaccination }\end{array}$} & $\begin{array}{c}\text { Serological response } \\
\text { amooth } \\
\text { antigen }\end{array}$ & Rough antigen \\
\hline Vaccination & RB51 & $5-8$ months & -ve & +ve $^{*}$ 2-19 w.p.v \\
\hline Revaccination & RB51 & $20-22$ months & -ve & +ve 2-22 w. p.v \\
\hline
\end{tabular}

* All cows seroconverted

w. p.v = weeks postvaccination

Table 2: Monitoring the serological immune response of cows of group II

\begin{tabular}{|c|c|c|c|c|}
\hline \multicolumn{2}{|c|}{ Used vaccine } & \multirow{2}{*}{$\begin{array}{c}\text { Age of } \\
\text { vaccination }\end{array}$} & \multicolumn{2}{c|}{ Serological response } \\
\cline { 3 - 5 } & Smooth antigen & Rough antigen \\
\hline Vaccination & S19 & 5-8 months & +ve* 2-28 w.p.v & -ve \\
\hline Revaccination & RB51 & 20-22 months & -ve & +ve 2-20 w.p.v \\
\hline
\end{tabular}

* All animals seroconverted

w.p.v = weeks postvaccination 
Table 3: Monitoring the serological immune response of cows of group III

\begin{tabular}{|c|c|c|c|c|}
\hline \multicolumn{2}{|c|}{ Used vaccine } & Age of & \multicolumn{2}{c|}{ Serological response } \\
\cline { 4 - 5 } & vaccination & Smooth antigen & Rough antigen \\
\hline Vaccination & S19 & 5-8 months & +ve* 2-28 w.p.v & -ve \\
\hline
\end{tabular}

* All cows seroconverted

Re-examination after one year showed that all cows remained seronegative throughout the experiment

Table 4: Bacteriological findings.

\begin{tabular}{|c|c|c|c|}
\hline \multirow{2}{*}{ Cow group } & \multicolumn{2}{|c|}{ Shedding of the vaccinal strain } & \multirow{2}{*}{ Abortion } \\
\cline { 2 - 3 } & Milk & Vaginal discharges & \\
\hline I & One cow $+\mathrm{ve}^{*}$ & 2 cows $+\mathrm{ve}^{* *}$ & -ve \\
\hline II & -ve & $-\mathrm{ve}$ & -ve \\
\hline III & -ve & -ve & -ve \\
\hline
\end{tabular}

* Sample of 3 days post parturition

** Samples of one and 3 days post parturition

\section{DISCUSSION}

The humoral immune response of RB51 vaccinated calves of group I, using rough antigen, revealed that sera of all vaccinates reacted positively at the $2^{\text {nd }}$ week post vaccination. Seroconvesion continued in some calves up to 19 weeks post vaccination, Table (1). Such humoral immune response is directed primarily to the outer membrane proteins but not to the lipopolysaccharide-O antigen as reported by Schurig et al. (1991).

On the other hand, sera of vaccinated calves showed complete negative results using the conventional tests and employing smooth antigen, these tests detect only antibodies against lipopolysaccharide-O antigen which characterize only the smooth brucella strains while RB51is a rough mutant which is devoid of lipopolysaccharide-O chain, Stevens et al. (1995). Revaccination of these cows using the same vaccine at 20-22 months age revealed the same serological profile and antibodies against the rough antigen continued up to 22 weeks post vaccination. 
The above mentioned data confirmed that both vaccination and revaccination of adult cows using RB51 does not induce detectable antibodies against the smooth antigen employing the conventional tests used for detection of brucella infection and consequently it does not interfere with surveillance programs.

Serological examination of S19 vaccinates of group II, using the conventional serological tests, revealed that all calves seroconverted at the $2^{\text {nd }}$ week post-vaccination and some continued up to 28 weeks postvaccination, Table (2). Revaccination of these animals at 20-22 months using RB51 vaccine of age resulted in development of antibodies against the rough antigen up to up to 22 weeks post-vaccination. On the other hand, antibodies against the smooth antigen could not be detected. The obtained results confirmed the lack of seroconversion of animals that previously vaccinated with S19 as calfhood vaccination when revaccinated with RB51 vaccine as adults indicating the safety of such procedure. RB51 vaccine was described as a safe procedure by Zambrano et al. (1995) and Palmer et al. (1997).

Cows of group III that were vaccinated using S19 as calves of 5-8 months showed the same pattern of calves of group II. Examination of these animals after nearly one year revealed that all cows maintained their negative serological status when became adults.

Evaluation of the trials employed in this study on bacteriological basis, Table (4), showed that among the cows of group I, one cow shed RB51 vaccinal strain in milk which could be detected only from the sample collected 3 days post-parturition and two cows shed the organism one and 3 days post-parturition in their vaginal discharges including the cow whose milk was bacteriolgically positive.

This indicates that RB51 can be shed in milk or vaginal discharges of adult RB51 vaccinated cows especially when they are vaccinated during pregnancy. Shedding of RB51 vaccinal strain in vaginal discharges was reported by Samartino et al. (2000) and Hosein et al. (2005). Shedding in milk was also reported by Samartino et al. (2000) who suggested that shedding of RB51 in milk can actually benefit herd immunity due to ingestion of these organisms by young calves to induce protective immunity.

On the contrary, such finding may lead me to believe that such situation may be hazardous from the epizootiological as well as the epidemiological points of view as it may lead to cases of latent infection in calves due to ingestion of the organism in milk as well as it may result in human infection that will be difficult to be diagnosed by the current 
conventional tests which are designed to detect infection by smooth brucella strains.

On the other hand, concerning cows that were vaccinated with $\mathrm{S} 19$ as a calfhood vaccine and revaccinated as adults with RB51 vaccine, there was no shedding of the vaccinal strain neither in milk nor in vaginal discharges. Such results may be attributed to the protective immunity induced by the calfhood S19 vaccination.

\section{ACKNOWLEDGEMENT}

I would like to thank Prof. Dr. H. I. Hosein Prof. of infectious diseases, Faculty Vet. Med. Beni-Suef and Prof. Dr. M.N. Shalaby, Chief researcher, Brucella department, Animal Health Research Institute, Dokki, Egypt for their valuable help and advice.

\section{REFERENCES}

Adone, R. and Ciuchini, F. (2001): Brucella abortus RB51 and hot saline extract from Brucella ovis as antigens in a complement fixation test used to detect sheep vaccinated with brucella abortus RB51. Clinical and diagnostic laboratory.

Alton, G.G.; Jones, L.M.; Angus, R.D. and Verger, J.M. (1988): Techniques for the brucellosis Laboratory. INRA. Publication, Paris, ISEN, France.

Covert, J.; Eskra, L. and Splitter, G. (2005): Isolation of Brucella abortus total RND from Brucella abortus infected murine RAW macrophages.

Hosein, H.I.; Dawood, F.Z. and Elsheery, M.N. (2002): Evaluation of the policy of test and slaughter for control of brucellosis in Egypt. $10^{\text {th }}$ sci. con. 2002, Fac. Vet. Med. Assuit Univ. J. of Microbiol. Methods 60, 283-293 (2005).

Hosein, H.I.; Shalaby, M.N. and Azzam, R.A. (2005): Abortion and shedding of Brucella aborbtus RB51 in vaginal exudates of aborted recently vaccinated cows. $4^{\text {th }}$ sci.con., Fac. Vet. Med. Beni-Suef Univ.

Morgan, W.J.B.; Makinnon, D.J.; Gill, K.P.W.; Cower, S.G.M. and Norris, P.L.W. (1978): Standard laboratory techniques for the diagnosis of brucellosis. Report series No.1, Weybridge, Cent. Vet. Lab., England. 
Olsen, S.C.; Stevens, M.G.; Cheville, N.F. and Schurig, G.G. (1997): Experimental use of a dot-blot assay to measure serologic responses of cattle vaccinated with Brucella abortus strain RB51. J. Vet. Diag. Investig. 9, 363-367 (1997).

Palmer, M.V.; Olsen, S.C. and Cheville, N.F. (1997): Safety and immunogenicity of Brucella abortus strain RB51 vaccine in pregnant cattle. Am. J. Vet. Res. 58, $472-477$ (1997).

Samartino, L.E.; Fort, M.; Gregoret, R. and Schurig, G.G. (2000): Use of Brucella abortus vaccine Strain RB51 in pregnant cows after calfhood vaccination with Strain 19 in Argentina. Preventive Veterinary Medicine 45, 193-199 (2000) immunology 122, 8, No.1, 1-9 (2001).

Salem, A.A. and Hosein, H.I. (1990): Brucella strain Prevalent in Egypt. Assuit Vet. J. 22(44), 160-163(1990).

Schurig, G.G.; Roop, R.M.; Bagchi, T.; Boyle, S.; Buhrman, D. and Sriranganathan, N. (1991): Biological properties of RB51: a stable rough strain of Brucella abortus. Vet. Microbiol. 28, 171-188.

Schurig, G.G.; Srirangananthan, N. and Corbel, M.J. (2002): Brucellosis vaccines: Past, Present and future Vet. Microbiol. (90) 479-496 (2002).

Soliman, H.S. (2006): PhD thesis,infectious diseases, Fac. Vet. Med. Beni-Suef University.

Stevens, M.G.; Olsen, S.G.; Pough, G.W. and Breen, D. (1995): Comparison of immune response and ressistance to brucellosis in mice vaccinated with Brucella abortus S19 or RB51. Infection and immunity, 63 (1), 264-269.

Zambrano, A.J.; Villava, F.M.; Schurig, G.G. and Cherowonogrodzky, $J$. (1995): Prelimenary results for vaccination of pregnant cattle with Brucella abortus Strain 19 or Brucella abortus Strain RB51 Arch. Med. Vet. xxvII 119-123 (1995). 